\title{
Burn-Up Measurements on Dissolver Solution of Mixed Oxide Fuel Using HPLC-Mass Spectrometric Method
}

\author{
S. Bera, R. Balasubramanian, Arpita Datta, R. Sajimol, S. Nalini, T. S. Lakshmi Narasimhan, \\ M. P. Antony, N. Sivaraman", K. Nagarajan, P. R. Vasudeva Rao \\ Chemistry Group, Indira Gandhi Centre for Atomic Research, Kalpakkam, India \\ Email: " sivaram@igcar.gov.in
}

Received July 20, 2013; revised August 23, 2013; accepted September 23, 2013

Copyright (C) 2013 S. Bera et al. This is an open access article distributed under the Creative Commons Attribution License, which permits unrestricted use, distribution, and reproduction in any medium, provided the original work is properly cited.

\begin{abstract}
Burn-up measurement on an irradiated mixed oxide (MOX) test fuel pellet was carried out through measurements on the dissolver solution by HPLC-Thermal Ionization Mass Spectrometric (TIMS) technique. The studies carried out using HPLC as well as TIMS for quantification of burn-up value are described. While in one case, both the separation and determination of elements of interest (U, Pu and $\mathrm{Nd}$ ) were carried out by HPLC; in another case, TIMS technique was used to quantify them from the HPLC separated fractions. The rapid separation procedures developed in our laboratory earlier were employed to isolate pure fractions of the desired elements. The individual lanthanide fission products (La to $\mathrm{Eu})$ were separated from each other using dynamic ion-exchange chromatographic technique whereas uranium and plutonium were separated from each other using reversed phase chromatographic technique. The pure fractions of $\mathrm{U}, \mathrm{Pu}$ and Nd obtained after HPLC separation procedure for "spiked" and "unspiked" dissolver solutions were used in TIMS measurements for the first time in our laboratory. In TIMS analysis, isotopic abundances of uranium, plutonium and neodymium fractions obtained from HPLC separation procedure on an "unspiked" fuel sample were measured. For the determination of $\mathrm{U}, \mathrm{Pu}$ and $\mathrm{Nd}$ by isotopic dilution mass spectrometric technique (IDMS), known quantities of tracers enriched in ${ }^{238} \mathrm{U},{ }^{240} \mathrm{Pu}$ and ${ }^{142} \mathrm{Nd}$ were added to the pre-weighed dissolver solution and subjected to HPLC separation procedures. The isotope ratios viz. ${ }^{142} \mathrm{Nd} /\left({ }^{145} \mathrm{Nd}+{ }^{146} \mathrm{Nd}\right),{ }^{238} \mathrm{U} /{ }^{233} \mathrm{U}$ and ${ }^{240} \mathrm{Pu} /{ }^{239} \mathrm{Pu}$ in the pertinent "spiked" fractions were subsequently measured by TIMS. The spikes were pre-standardized in our laboratory employing reverse isotopic dilution technique against the standard solutions available in our laboratory (for ${ }^{238} \mathrm{U},{ }^{239} \mathrm{Pu}$ and ${ }^{142} \mathrm{Nd}$, standard solutions of ${ }^{233} \mathrm{U},{ }^{239} \mathrm{Pu}$ (of higher abundance than in the sample) and ${ }^{150} \mathrm{Nd}$ were employed as spikes). The burn-up values from duplicate spiking experiments were computed based on the summation of ${ }^{145} \mathrm{Nd}+{ }^{146} \mathrm{Nd}$. The concentrations of neodymium, uranium and plutonium were also measured using HPLC with post-column derivatisation technique using aresenazo(III) as the post-column reagent. The atom \% burn-up computed from HPLC and TIMS techniques were in good agreement.
\end{abstract}

Keywords: MOX; Dissolver Solution; HPLC; TIMS; Uranium; Plutonium; Neodymium

\section{Introduction}

The burn-up of a fuel is a measure of the number of fissions undergone by the fuel [1]. The atom percent burnup expression is essentially ratio of the number of fissions that have occurred to the total heavy atoms initially present. Determination of burn-up is thus an important parameter for the study of fuel performance, an indication of energy production from unit mass of fuel. The measurement of burn-up on dissolver solution of fuel subjected to high burn-up is challenging due to the high levels of radioactivity associated with the fuel. Various

${ }^{*}$ Corresponding author. methods have been developed to measure the burn-up of spent nuclear fuels [1-8]. Among these, isotope dilution mass spectrometric technique (IDMS) is recognized as an established technique [2]. The HPLC based techniques have also been developed in our laboratory for rapid and accurate determination of burn-up of nuclear reactor fuels $[5,7]$.

The mass spectrometric method uses the isotopic dilution technique to measure the concentrations of the burnup monitor and the residual heavy elements present in the spent fuel to deduce the burn-up. The criteria for choosing a particular fission product monitor stems from the desired nuclear properties such as fission yield, neutron 
absorption cross section, decay constant and its migration into the fuel matrix to give reliable burn-up value [1]. By far the most widely used burn-up monitor for mass spectrometric measurements is ${ }^{148} \mathrm{Nd}$ based on the above considerations $[1,2,6]$.

The burn-up (BU) is obtained from the relation:

$\mathrm{BU}$ (in at $\%$ fissions $)=100\left(\mathrm{~N}\left({ }^{\mathrm{M}} \mathrm{Nd}\right) / \mathrm{y}\left({ }^{\mathrm{M}} \mathrm{Nd}\right)\right) /[\mathrm{N}(\mathrm{U})+$ $\left.\mathrm{N}(\mathrm{Pu})+\left(\mathrm{N}\left({ }^{\mathrm{M}} \mathrm{Nd}\right) / \mathrm{y}\left({ }^{\mathrm{M}} \mathrm{Nd}\right)\right)\right]$.

where " $\mathrm{N}$ " represents the concentration (number of atoms/g of the dissolver solution) of the nuclide or element given in the parentheses; and " $y$ " represents the fractional fast-fission yield for ${ }^{\mathrm{M}} \mathrm{Nd}$. In this study, "M" refers to mass numbers of $\mathrm{Nd}$ : 148,145 , and 146 wherever applicable and the rationale behind considering these isotopes for computing the burn-up is discussed later.

In the present study, results on the determination of burn-up on dissolver solution of nuclear reactor fuel, namely uranium-plutonium mixed oxide (MOX) spent fuel by mass spectrometric method are discussed. The HPLC based techniques using dynamic ion-exchange (individual lanthanide separation) and reversed phase chromatography (uranium and plutonium) were employed for the determination of lanthanides and actinides [3$5,7]$.

The pure fractions of neodymium, uranium and plutonium required for mass spectrometric studies are conventionally obtained using time consuming traditional ionexchange chromatographic procedure using gravity flow. However, in the present study, these metal ion fractions were rapidly isolated employing HPLC technique, i.e. the dissolver solution was directly injected into the HPLC system after appropriate dilutions for the isolation of desired fractions of fission products and actinides. The neodymium fraction required for TIMS measurements was obtained by its isolation from other lanthanide fission products using dynamic ion exchange chromatographic method, whereas pure fractions of uranium and plutonium were obtained using reversed phase chromatographic technique. The fractional fission and the atom percent fission were computed based on these measurements and the results were discussed.

\section{Experimental}

Mass spectrometric and HPLC determination of burn-up of MOX fuel pellets were carried out on a test irradiated fuel, discharged from Fast Breeder Test Reactor (FBTR) at Kalpakkam. The U-Pu mixed oxide fuel with $29 \% \pm$ $1 \% \mathrm{PuO}_{2}\left(76 \%{ }^{239} \mathrm{Pu}\right.$ in total plutonium $)$ and rest $\mathrm{UO}_{2}$ enriched in ${ }^{233} \mathrm{U}\left(53.5 \%{ }^{233} \mathrm{U}\right.$ in total uranium) was used. One of the irradiated fuel pellets was dissolved in $11 \mathrm{M}$ $\mathrm{HNO}_{3}$ medium in the hotcells. An aliquot of the dissolver solution containing uranium, plutonium, lanthanides and other fission products in $\mathrm{HNO}_{3}$ medium (with permissible external dose) was taken inside a fume hood, evapo- rated to near dryness under a heat lamp and re-dissolved in $8 \mathrm{M} \mathrm{HNO}_{3}$ medium. Subsequently, the solution was diluted with a solution of $\alpha$-HIBA and directly injected into the HPLC system with appropriate dilutions for the determination of lanthanide fission products, uranium and plutonium. The pure fraction of $\mathrm{Nd}$ was collected at an appropriate retention time and was analyzed for isotopic analysis by TIMS. Similarly, the pure $\mathrm{U}$ and $\mathrm{Pu}$ fractions for TIMS were collected from reversed phase chromatographic technique. Identical separation procedures were followed after the addition of spikes viz. ${ }^{238} \mathrm{U}$, ${ }^{239} \mathrm{Pu}$ and ${ }^{142} \mathrm{Nd}$. The samples (about $2 \mu \mathrm{g}$ in the case of uranium and plutonium and $1 \mu \mathrm{g}$ in the case of neodymium) were loaded onto a side filament of the triple filament assembly with Ta-Re-Ta configuration.

\subsection{HPLC Analysis}

The HPLC system (M/S JASCO, Japan) was set-up in fumehood for separation of fission product monitors and actinides. High pressure pumps used for the delivery of mobile phase and post-column reagent were placed outside the fumehood; Rheodyne sample injector, chromatographic column and detector were kept inside the fumehood. Reverse phase monolithic column (Merck) with dimensions, surface area, macroporous and mesoporous structure of $100 \mathrm{~mm} \times 4.6 \mathrm{~mm}, 300 \mathrm{~m}^{2} \mathrm{~g}^{-1}, 2 \mu \mathrm{m}$, and $13 \mathrm{~nm}$ respectively was used. The eluate from the chromatographic experiment was collected inside the fumehood. The data acquisition from the UV-Vis detector was connected to a computer through a Borwin software interface, which was kept outside the fumehood. Post-column derivatisation technique was employed for the detection of lanthanides and actinides. In this method, the effluent from the column was mixed with the coloring reagent, arsenazo (III) after the column using a " $\mathrm{T}$ " connector and the complex was passed on to a UV-Vis detector. The lanthanide and actinide (U, and $\mathrm{Pu}$ ) complexes were detected at $655 \mathrm{~nm}$. For the preparation of calibration plots, lanthanide samples (La-Sm) over the concentration range of 2 - $50 \mu \mathrm{g} / \mathrm{mL}$ (injected amount, 20 $\mu \mathrm{L})$ were injected into the HPLC system. In the reversed phase chromatographic study, uranium i.e. $\mathrm{UO}_{2}^{+2}(10-$ $100 \mathrm{ppm})$ and plutonium i.e. $\mathrm{Pu}$ (IV) (10 - 75 ppm) nitrate solutions were injected into the HPLC system for the calibration studies. Sodium nitrite was added to an aliquot of dissolver solution to ensure plutonium in its $\mathrm{Pu}(\mathrm{IV})$ oxidation state.

\subsection{Separation of Lanthanide Fission Products Using HPLC with Dynamic Ion-Exchange Column}

The reversed phase monolith column was modified into a dynamic ion-exchange support using water soluble mod- 
ifier, e.g., ion-pairing reagent, camphor-10-sulfonic acid (CSA) [9-11]. The lanthanides were separated and eluted using alpha hydroxy isobutyric acid ( $\alpha$-HIBA). The mobile phase $(0.02 \mathrm{M} \mathrm{CSA}+0.1 \mathrm{M} \alpha$-HIBA, $\mathrm{pH}$ adjusted to 3.1 with dil. $\mathrm{NH}_{3}$ ) was passed through the monolithic reversed phase column to establish a dynamic ion-exchange surface. About $30 \mathrm{~mL}$ of mobile phase was passed through the column to establish a dynamic ion-exchange surface.

\subsection{Separation and Determination of Uranium and Plutonium with HPLC Using Reversed Phase Chromatography}

Uranium and plutonium present in the dissolver solution were separated and determined by both dynamic ionexchange and reversed phase chromatographic techniques. Uranium as well as plutonium were not determined in the same run along with lanthanides since the $U$ and $\mathrm{Pu}$ peaks showed near saturation during the assay of the lanthanide fraction in the dynamic ion-exchange experiments. The dissolver solution was directly injected after appropriate dilution for the determination of uranium or plutonium.

The reversed phase HPLC technique using monolith support was also employed in the present work for the separation and determination of uranium $\left(\mathrm{UO}_{2}{ }^{+2}\right)$ and plutonium $\mathrm{Pu}$ (IV).

\subsection{Mass Spectrometric Analysis}

The isotopic ratios were measured using a multi collector thermal ionization mass spectrometer (ISOPROBE-T, $\mathrm{M} / \mathrm{S}$ ISOTOPX, UK). It is equipped with 20 sample turret with 9 Faraday cups and an axial SEM. The instrument uses a $90^{\circ}$ sector magnet designed with a $26.5^{\circ}$ oblique incidence to provide a better mass dispersion compared to old generation instruments. The samples were loaded on to a triple filament assembly.

\subsection{Experimental Conditions for TIMS}

The pure neodymium, uranium and plutonium fractions obtained from chromatographic separations were evaporated to near dryness and were re-dissolved in $8 \mathrm{M} \mathrm{HNO}_{3}$ medium. This procedure i.e. dissolution of fractions in $\mathrm{HNO}_{3}$ medium was repeated three times to minimize the organics (CSA and HIBA) during the loading of $\mathrm{Nd}, \mathrm{U}$ and $\mathrm{Pu}$ fractions on the tantalum filament.

Prior to running an isotopic ratio measurement program, collector gain calibration was done, since the measurements were done in static multicollection mode. The samples were first heated using an in-built program to ramp up the filament current slowly to $4.0 \mathrm{~A}$ and $1.0 \mathrm{~A}$ for central (ionization) and side (vaporization) filaments respectively. At this stage, $\mathrm{Re}^{+}$signal (usually about 60 -
$70 \mathrm{mV}$ ) was measured and the focus conditions optimized with the controls provided for various focus plates. Subsequently, the side filament currents were slowly increased to get minimum ion intensity for the peaks of interest. Once the "flat topped" isotopic peaks were obtained by proper focusing, all the peaks were checked for "coincidence" which signifies the exact placement of collectors for the dispersed beams. Subsequently, the sample filament current was slowly ramped to obtain the ion intensity around $1-2 \mathrm{~V}$ for major peak. In general, central filament and side filaments were heated at $5.4 \mathrm{~A}$ and 2.3 A respectively for a satisfactory analysis. The isotope ratios were obtained by comparing the ion intensities of all the beams acquired by the software. During the experiments, vacuum of around $3 \times 10^{-8}$ mbar at ion source and $4 \times 10^{-9} \mathrm{mbar}$ at analyzer was maintained using turbo molecular pump and ion pumps respectively, backed up by liquid nitrogen trap placed above the source chamber.

\section{Results and Discussion}

Figure 1 represents the chromatogram showing the lanthanides present in the dissolver solution separated from each other as well as resolved from uranium and plutonium under dynamic ion-exchange conditions. The fission product monitors, neodymium/lanthanum present in dissolver solution were well separated from uranium $\left(\mathrm{UO}_{2}{ }^{+2}\right)$ and $\mathrm{Pu}(\mathrm{IV})$ under the experimental condition with a mobile phase composition as follows: $0.02 \mathrm{M}$ $\mathrm{CSA}+0.1 \mathrm{M}$ HIBA, $\mathrm{pH}: 3.1$, flow rate: $2 \mathrm{~mL} / \mathrm{min}$. The concentrations of $\mathrm{La}, \mathrm{Ce}, \mathrm{Pr}$, and $\mathrm{Nd}$ were determined in the dissolver solution using a calibration plot. The concentrations of lanthanides (La, Ce, Pr, Nd and Sm) and actinides ( $\mathrm{U}$ and $\mathrm{Pu}$ ) in the dissolver solution of MOX fuel were estimated and the results are shown in Table 1. Uranium and plutonium were also separated and determined by reversed phase chromatographic technique (Figure 2).

\subsection{Computation of Burn-Up Using HPLC Technique}

The HPLC technique can provide only an elemental rather than an isotopic yield. When sum of concentrations of all isotopes of a fission product monitor element is used (total elemental yield) for determination of " $\mathrm{A}$ ", the fractional fission yield, " $y$ " is obtained by summing up the fractional fission yield of all isotopes of the fission monitor and dividing by 100 [1]. In the present study, for computing burn-up, we have examined the possibility of using three different lanthanides as fission product monitors, namely, Nd, La and Pr. The Nd isotopes produced in the fission are ${ }^{143} \mathrm{Nd},{ }^{144} \mathrm{Nd},{ }^{145} \mathrm{Nd},{ }^{146} \mathrm{Nd},{ }^{148} \mathrm{Nd}$ and ${ }^{150} \mathrm{Nd}$ for both ${ }^{233} \mathrm{U}$ and ${ }^{239} \mathrm{Pu}$ nuclides. The total $\mathrm{Nd}$ 


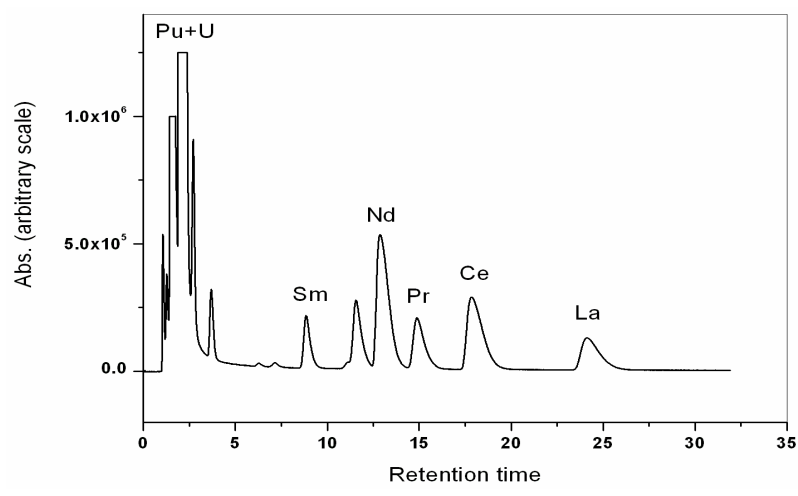

Figure 1. Direct injection of MOX dissolver solution into HPLC for separation and determination of lanthanide fission products. Mobile phase: 0.02 M CSA + 0.1 M HIBA, pH: 3.1, Flow rate: $2 \mathrm{~mL} / \mathrm{min}$; post-column reagent: Arsenazo(III) $\left(10^{-4} \mathrm{M}\right)$; flow rate: $1 \mathrm{~mL} / \mathrm{min}$; detection of lanthanide-arsenazo(III) complexes: $655 \mathrm{~nm}$. Sample: aliquot of MOX fuel $\sim 110 \mathrm{GWd} / \mathrm{t}$ dissolved in mobile phase and injected into HPLC.

Table 1. Estimation of lanthanides, uranium and plutonium in the dissolver solution.

\begin{tabular}{ccc}
\hline $\begin{array}{c}\text { Lanthanide fission products/ } \\
\text { actinides }\end{array}$ & $\begin{array}{c}\text { Amount per gram of } \\
\text { dissolver solution }\end{array}$ & $\begin{array}{c}\text { Atom \% } \\
\text { burn-up }\end{array}$ \\
\hline Lanthanum (La-139) & $204.9 \mu \mathrm{g}$ & 10.8 \\
Cerium (Ce-140, 142) & $401.1 \mu \mathrm{g}$ & \\
Praseodymium (Pr-141) & $201.6 \mu \mathrm{g}$ & \\
Neodymium (Nd-143, 144, & $573.2 \mu \mathrm{g}$ & $10.5^{*}$ \\
145, 146, 148, 150) & $11^{\mathrm{S}}$ \\
Samarium & $123.1 \mu \mathrm{g}$ & \\
Europium & $8.5 \mu \mathrm{g}$ & \\
Uranium & $32.85 \mathrm{mg}$ & \\
Plutonium & $13.28 \mathrm{mg}$ \\
\hline
\end{tabular}

HPLC experimental conditions: mobile phase: 0.02 M CSA; 0.1 M HIBA; pH: 3.1 (lanthanide fission products separation); 0.1 M HIBA; pH: 3.75 (U-Pu separation). " ' $y$ ' value used was 0.1743 , where ' $y$ ' was cumulative yield of all $\mathrm{Nd}$ isotopes exclusively from ${ }^{233} \mathrm{U}$ fast fissions. ${ }^{~ ' ~} \mathrm{y}$ ' value used was 0.1641 , where ' $\mathrm{y}$ ' was cumulative yield of all $\mathrm{Nd}$ isotopes exclusively from ${ }^{239} \mathrm{Pu}$ fast fissions. ' ‘ $\mathrm{y}$ ' value used was 0.1696 , where 'y' was computed based on $54.2 \%$ fast fissions from ${ }^{233} \mathrm{U}$ and $45.8 \%$ fast fissions from ${ }^{239} \mathrm{Pu}$. Fractional fissions were computed using TIMS. Burn-up computed (HPLC technique) as follows: Atom percent fission $=\{[\mathbf{A} / \mathbf{y}]\} /\{\mathbf{H}+[\mathbf{A} / \mathbf{y}]\} \mathbf{x}$ 100; where "A" is the number of atoms of fission product monitor ( $\mathrm{Nd}$ or $\mathrm{La}$ ), ' $\mathrm{y}$ ' is the effective fractional fission yield for " $\mathrm{A}$ " [12] and " $\mathrm{H}$ " is the residual heavy element $(\mathrm{U}+\mathrm{Pu})$ atoms in the dissolver solution.

yield is $16.41 \%$ and $17.43 \%$ for ${ }^{239} \mathrm{Pu}$ and ${ }^{233} \mathrm{U}$ respectively, differing by about $6 \%$ [12]. The fission product $\mathrm{La}$ is mainly formed as mono isotopic $\left({ }^{139} \mathrm{La}\right)$ and allows the use of chemical technique for its assay. However, the La yields for ${ }^{239} \mathrm{Pu}$ and ${ }^{233} \mathrm{U}$ fissions are $5.83 \%$ and $6.55 \%$ respectively, differing by $\sim 11 \%$ [12]. Similarly, use of praseodymium (produced as ${ }^{141} \mathrm{Pr}$ ) also results in a difference in the " $y$ " between ${ }^{239} \mathrm{Pu}(5.62 \%)$ and ${ }^{233} \mathrm{U}$ fissions $(7.00 \%)$ by about $20 \%$ [12]. Thus use of total

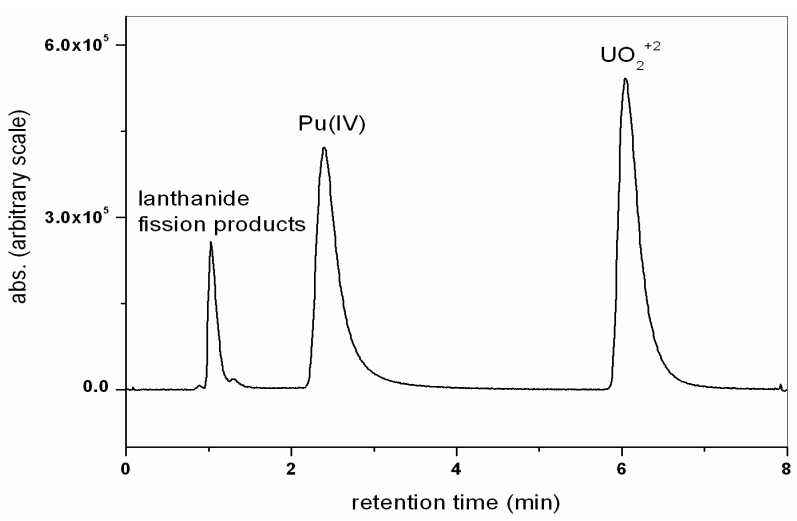

Figure 2. Separation and determination of uranium and plutonium present in dissolver solution of MOX fuel by reversed phase chromatography. Mobile phase: 0.1 M HIBA, pH: 3.75, Flow rate: $2 \mathrm{~mL} / \mathrm{min}$; PCR with arsenazo(III) at $655 \mathrm{~nm}$. Sample: dissolver solution of MOX. (U and Pu fractions from these studies taken for IDMS). Concentrations of $U$ and $P u$ were $33 \mu \mathrm{g} / \mathrm{mL}$ and $13 \mu \mathrm{g} / \mathrm{mL}$ respectively.

$\mathrm{Nd}$ as fission product monitor can be regarded as better option than use of Pr or La. Further, the difference in "y" gets minimized by employing fractional fission contribu tions from ${ }^{233} \mathrm{U}$ and ${ }^{239} \mathrm{Pu}$ for computing atom \% burn-up. The atom \% fission deduced from the HPLC measurements are summarized in Table 1.

\subsection{Isotopic Ratio Measurements and Atom \% Burn-Up}

The isotopic composition of uranium in the dissolver solution was found to be: ${ }^{238} \mathrm{U}: 55.09 \%$; ${ }^{233} \mathrm{U}: 43.23 \%$; ${ }^{234} \mathrm{U}: 1.25 \%$; ${ }^{235} \mathrm{U}: 0.397 \%$; and ${ }^{236} \mathrm{U}: 0.036 \%$; for Plutonium, the values were: ${ }^{239} \mathrm{Pu}: 72.80 \% ;{ }^{240} \mathrm{Pu}: 24.27 \%$; ${ }^{241} \mathrm{Pu}: 1.56 \%$; ${ }^{242} \mathrm{Pu}: 1.14 \%$; and ${ }^{238} \mathrm{Pu}: 0.23 \%$. The isotopic composition of fission product neodymium was: ${ }^{143} \mathrm{Nd}: 29.23 \% ;{ }^{144} \mathrm{Nd}: 23.81 ;{ }^{145} \mathrm{Nd}: 18.75 \% ;{ }^{146} \mathrm{Nd}$ : $15.06 \%$; ${ }^{148} \mathrm{Nd}: 8.69 \%$; and ${ }^{150} \mathrm{Nd}: 4.46 \%$. The isotopic composition data are given in Table 2. Since the test fuel is a combination of Pu recycled from thermal reactor and uranium enriched in ${ }^{233} \mathrm{U}$ to provide more fissile content, the fissions would be mainly contributed by ${ }^{239} \mathrm{Pu}$ and ${ }^{233} \mathrm{U}$. Since one of the criteria for choosing a burn-up monitor is uniform fission yield from various sources of fission [1], different isotopes of neodymium were examined for deducing burn-up for this type of test fuel and the pair ${ }^{145} \mathrm{Nd}+{ }^{146} \mathrm{Nd}$ having closely similar fast fission yields from ${ }^{233} \mathrm{U}(5.65 \%)$ and ${ }^{239} \mathrm{Pu}(5.59 \%)$ was chosen [12]. The ratios of neodymium isotopes i.e. $\left[{ }^{145} \mathrm{Nd}+\right.$ $\left.{ }^{146} \mathrm{Nd}\right] /\left[{ }^{150} \mathrm{Nd}\right]$ are widely different for these two sources of fission (12.12 for ${ }^{233} \mathrm{U}$ and 5.48 for $\left.{ }^{239} \mathrm{Pu}\right)$. Hence the mass spectrometric data for these isotopes have been chosen for computing the fractional fissions. A similar approach was followed to compute fractional fissions in 
our earlier studies using HPLC [5]. The fractional fission contribution of ${ }^{233} \mathrm{U}$ and ${ }^{239} \mathrm{Pu}$ towards total fission is $54.2 \%$ and $45.8 \%$ respectively. The atom \% burn-up deduced from the concentrations of $\mathrm{U}, \mathrm{Pu}$ and $\mathrm{Nd}$ was 10.8 (total $\mathrm{Nd}$ as monitor), $10.9\left(\mathrm{Nd}^{148}\right.$ as monitor) and $10.9\left(\mathrm{Nd}^{145+146}\right.$ as monitors) and are given in Table 3 .

The possible source of errors contributing to the computed burn-up are those arising from 1) assay of fission product monitor, uranium and plutonium, 2) data on the fission yield of the fission product monitor and 3) computation of fractional fissions from ${ }^{233} \mathrm{U}$ and ${ }^{239} \mathrm{Pu}$ from

Table 2. Isotope ratios and abundances.

\begin{tabular}{cccccc}
\hline Isotope & $\begin{array}{c}\text { Isotope } \\
\text { M(i) } \\
\text { M(i)/M(ref) }\end{array}$ & $\begin{array}{c}\text { Relative } \\
\text { error in } \\
\text { \% in } \\
\text { isotope } \\
\text { ratio }\end{array}$ & $\begin{array}{c}\text { Atom } \\
\text { fraction of } \\
\text { the isotope } \\
\text { M(i) }\end{array}$ & $\begin{array}{c}\text { Relative } \\
\text { error in } \\
\text { \% in } \\
\text { atom } \\
\text { fraction }\end{array}$ & $\begin{array}{c}\text { Mass \% } \\
\text { of the } \\
\text { isotope } \\
\text { M(i) }\end{array}$ \\
\hline URANIUM: M (REF) $=$ 238; AVERAGE ATOMIC WEIGHT $=\mathbf{2 3 5 . 8 0}$ \\
238 & 1 & - & $5.457 \times 10^{-1}$ & 0.058 & 55.094 \\
234 & $2.302 \times 10^{-2}$ & 1.13 & $1.256 \times 10^{-2}$ & 1.13 & 1.247 \\
235 & $7.301 \times 10^{-3}$ & 3.23 & $3.984 \times 10^{-3}$ & 3.23 & 0.397 \\
236 & $6.63 \times 10^{-4}$ & 25.54 & $3.62 \times 10^{-4}$ & 25.5 & 0.036 \\
233 & $8.014 \times 10^{-1}$ & 0.12 & $4.374 \times 10^{-1}$ & 0.135 & 43.226
\end{tabular}

Plutonium: M (REF) = 239; AVERAGE ATOMIC WEIGHT $=239.36$

$\begin{array}{cccccc}239 & 1 & - & 7.289 \times 10^{-1} & 0.017 & 72.802 \\ 238^{\mathrm{a}} & 3.149 \times 10^{-3} & 2.0 & 2.296 \times 10^{-3} & 2.0 & 0.228 \\ 240 & 3.320 \times 10^{-1} & 0.05 & 2.420 \times 10^{-1} & 0.053 & 24.272 \\ 241 & 2.125 \times 10^{-2} & 0.56 & 1.549 \times 10^{-2} & 0.562 & 1.560 \\ 242 & 1.543 \times 10^{-2} & 0.56 & 1.125 \times 10^{-2} & 0.561 & 1.137\end{array}$

NEODYMIUM: M (REF) = 143; AVERAGE ATOMIC WEIGHT $=144.70$

\begin{tabular}{cccccc}
143 & 1 & - & $2.959 \times 10^{-1}$ & 0.051 & 29.230 \\
144 & $8.090 \times 10^{-1}$ & 0.09 & $2.394 \times 10^{-1}$ & 0.105 & 23.812 \\
145 & $6.324 \times 10^{-1}$ & 0.16 & $1.872 \times 10^{-1}$ & 0.169 & 18.745 \\
146 & $5.045 \times 10^{-1}$ & 0.13 & $1.493 \times 10^{-1}$ & 0.143 & 15.058 \\
148 & $2.873 \times 10^{-1}$ & 0.20 & $8.503 \times 10^{-2}$ & 0.211 & 8.692 \\
150 & $1.456 \times 10^{-1}$ & 0.51 & $4.308 \times 10^{-2}$ & 0.510 & 4.464 \\
\hline
\end{tabular}

a) Deduced by combining mass spectrometric and alpha spectrometric results; error estimated to be $2 \%$.

Table 3. Computation of burn-up using different isotopes of Nd determined by IDMS technique.

$\begin{array}{ccc}\begin{array}{c}\text { Fission } \\ \text { product } \\ \text { monitors }\end{array} & \begin{array}{c}\text { Total number of atoms } \\ \text { determined per gram of } \\ \text { dissolver solution }\end{array} & \begin{array}{c}\text { Atom \% } \\ \text { burn-up }\end{array} \\ \text { Total Nd } & 2.28 \times 10^{22} & 10.8 \\ { }^{148} \mathrm{Nd} & 1.94 \times 10^{21} & 10.9 \\ { }^{(145+146)} \mathrm{Nd} & 7.68 \times 10^{21} & 10.9\end{array}$

*Total residual heavy element atoms $(\mathrm{U}+\mathrm{Pu})$ determined per gram of dissolver solution: $11.1 \times 10^{23}$. isotopic measurements. The uncertainties in the assay of fission monitor, and heavy elements are minimized by the use of certified standards to $<1 \%$. The uncertainty in the yields of fission monitors (e.g. Nd) obtained from literature is $\sim 1 \%-2 \%$. The overall uncertainty arising from the individual contributions to the atom percent fission could extend to a maximum of $3 \%-5 \%$.

\section{Conclusion}

The rapid separation technique using dynamic ion exchange chromatographic technique was demonstrated for the separation of pure fractions of uranium, plutonium, and lanthanide fission products present in the dissolver solution of a mixed oxide fuel. Reversed phase chromatographic technique was employed for isolation of pure fractions of uranium and plutonium as well as for their assay in the dissolver solution. The pure fractions of neodymium, uranium and plutonium required for TIMS were isolated from the dissolver solutions using HPLC technique. Isotope dilution mass spectrometric method was employed to estimate different isotopes of neodymium, uranium and plutonium present in the dissolver solution. Fractional fissions from ${ }^{233} \mathrm{U}$ and ${ }^{239} \mathrm{Pu}$ were determined from these measurements. The atom percent fission (burnup) was computed from these data.

\section{Acknowledgements}

Authors thank Dr. K. Devan and Mr. C.R. Venkatasubramani for discussions on the reactor physics data.

\section{REFERENCES}

[1] J. E. Rein and B. F. Rider, "TID-17385, Burn-Up Determination of Nuclear Fuels," Progress Report, AEC Research and Development Report, 1962.

[2] ASTM Standards E, "Standard Test Method for Atom Percent Fission in Uranium and Plutonium Fuel (Neodymium-148 Method)," ASTM Standards E321-96, 2005.

[3] C. H. Knight, R. M. Cassidy, B. M. Recoskie and L. W. Green, "Dynamic Ion Exchange Chromatography for Determination of Number of Fissions in Thorium-Uranium Dioxide Fuels," Analytical Chemistry, Vol. 56, No. 3, 1984, pp. 474-478. doi:10.1021/ac00267a041

[4] R. M. Cassidy, S. Elchuk, N. L. Elliot, L. W. Green, C. H. Knight and B. M. Recoskie, "Dynamic Ion Exchange Chromatography for the Determination of Number of Fissions in Uranium Dioxide Fuels," Analytical Chemistry, Vol. 58, No. 6, 1986, pp. 1181-1186. doi: $10.1021 / \mathrm{ac} 00297 \mathrm{a} 045$

[5] N. Sivaraman, S. Subramaniam, T. G. Srinivasan and P. R. Vasudeva Rao, "Burn-Up Measurements on Nuclear Reactor Fuels Using High Performance Liquid Chromatography," Journal of Radioanalytical and Nuclear Chemistry, Vol. 253, No. 1, 2002, pp. 35-40.

doi:10.1023/A:1015800114488 
[6] R. Balasubramanian, D. Darwin Albert Raj, S. Nalini and M. Sai Baba, "Mass Spectrometric Studies on Irradiated (U, Pu) Mixed Carbide Fuel of FBTR," International Journal of Nuclear Energy Science and Technology, Vol. 1, No. 2-3, 2005, pp. 197-203.

[7] A. Datta, N. Sivaraman, T. G. Srinivasan and P. R. Vasudeva Rao, "Single Stage Dual Column HPLC Technique for Separation and Determination of Lanthanides in Uranium Matrix-Application to Burn-Up Measurement on Nuclear Reactor Fuel," Nuclear Technology, Vol. 182, 2013, pp. 84-97.

[8] P. G. Jaison, N. M. Raut and S. K. Aggarwal, "Direct Determination of Lanthanides in Simulated Irradiated Thoria Fuels Using Reversed-Phase High-Performance Liquid Chromatography," Journal of Chromatography A, Vol. 1122, No. 1-2, 2006, pp. 47-53.

doi:10.1016/j.chroma.2006.04.037
[9] P. R. Vasudeva Rao, N. Sivaraman and T. G. Srinivasan, "Studies of Lanthanide Separation with HPLC," In: Encyclopedia of Chromatography, Taylor \& Francis, 2005.

[10] A. Datta, N. Sivaraman, T. G. Srinivasan and P. R. Vasudeva Rao, "Rapid Separation of Lanthanides and Actinides on Small Particle Based Reverse Phase Supports," Radiochimica Acta, Vol. 98, 2010, pp. 277-285. doi:10.1524/ract.2010.1715

[11] A. Datta, N. Sivaraman, T. G. Srinivasan and P. R. Vasudeva Rao, "Liquid Chromatographic Behaviour of Lanthanide and Actinides on Monolith Supports," Radiochimica Acta, Vol. 99, 2011, pp. 275-283. doi:10.1524/ract.2011.1816

[12] E. A. C. Crouch, "Atomic Data and Nuclear Data Tables: Fission Product Yields from Neutron Induced Fission," Academic Press, New York and London, Vol. 19, 1977. 